\title{
Investigating the relationship between job satisfaction, communication style, employee behavior in conflict situations
}

\author{
Gabriela Caldarescu ${ }^{1}$, Laura Florea $^{1}$, Nicoleta Monica Lohan $^{2}$, and Mihai-Adrian \\ Bernevig $^{2 *}$ \\ ${ }^{1}$ Labor Inspectorate Iasi, Fire Mill Road no. 31, 707410 Iasi, Romania \\ 2"'Gheorghe Asachi”' Technical University of Iasi, Faculty of Materials Science and Engineering, D. \\ Mangeron Blv., no. 41, 700050 Iasi, Romania
}

\begin{abstract}
This study was designed to test the relationship between job satisfactions, communication style and conflict behaviour of employees in the public system, respectively in the territorial labour inspectorates. Research responds to practical needs highlighted by organizational psychology to identify the sources and dimensions that prevail and make the individual's perception of the organization lead to increased job satisfaction. However, the paper is not without methodological limits, represented by the use of self-report evaluation questionnaires that could involve poor identification and reporting, by the tendency of the facade that appears when the subject is not honest, offers answers that do not reflect its true feelings, principles and values, tends to avoid the appropriate responses to the state, only to leave a good impression, determine a positive judgment, placement in a situation of appreciation, or out of a desire to help the researcher in confirming the study hypothesis. The paper provides additional information for the scientific community, and can also be a starting point for other research by methodologically improving and bringing to the fore variables that can have a significant contribution to job satisfaction in civil servants, the subject being of maximum interest in the current context when a qualitative increase of services for employees and employers is desired.
\end{abstract}

\section{Introduction}

The purpose of this paper is to emphasize the significance within an organization of job satisfaction and the relations it has with the method of conflicts settlement and communication. This paper represents a research conducted within the territorial labor inspectorates. Effective communication affects a wide variety of components within an organization and can help in achieving a greater success for the organization [1]. Conflicts are inherent in any interpersonal relationship, but their management is defining for the personal balance and performance of any organization. Conflict management is based on the principle that not all conflicts can be settled, but learning how to manage conflicts can reduce

\footnotetext{
${ }^{*}$ Corresponding author: mihaibernevig@gmail.com
} 
the chances of unproductive escalation. Gupta and Joshi (2008) highlighted the transitions in conflicting thoughts; thus, the traditional option considers that the conflict is harmful and should be avoided, therefore the conflict was viewed negatively and was used as synonymous with the terms of violence, destruction and irrational. On the other hand, the modern point of view is based on the belief that it is not only a negative force in a group, but it is also necessary for a group to function effectively. This approach encourages the conflict, in the meaning that if the group is harmonious, peaceful and cooperative, it is prone to become static and to not respond to the needs for change and innovation. Initially, job satisfaction was thought to be a general attitude that ranged from low to very high. Over time, there have been talks of a global satisfaction index, in the meaning that it would be a total score of people's attitudes towards the various aspects of their work or their average. It has been observed that the way people relate their work contributes to a number of distinct factors, such as salary, work they carry out, the relationship with the managers and subordinates, all contributing to their personal and professional satisfaction related to the work they carry out [2].

\section{Concepts of communication, conflict and work satisfaction}

\subsection{Communication}

The concept of communication can be defined as an exchange of ideas, opinions, facts or emotions between two or more people in order to create a common ground of understanding. Communication represents a process of transmitting information and messages from one person to another, involving at least two people, namely the existence of a sender and a receiver. The sender develops and sends a message to the receiver and the goal is to reach a common understanding between the sender and the receiver. In other words, communication plays a key role in balancing individual and organizational goals. A representative definition belongs to M. Zlate (2008): "Communication is the exchange of information, messages, meanings between two or more sources (psychological and non-psychological) in order to influence one of them." [3].

\subsection{Conflict}

The concept of conflict or of a conflict situation is a situation where two or more values, perspectives and opinions are of a contradictory nature, have not yet been aligned or have not yet been agreed, because whenever two people interact, there are chances of a difference of opinion. A simple definition for conflict is experienced when a person perceives that his or her needs or desires are likely to be affected. Slaikeu and Hasson (1998) argue that one or more of the following are present in every conflict: denial, lack of skills, lack of information, conflicting interests or values, psychopathology, type of personality, scarce resources, organizational deficiencies, selfishness or bad intentions [4].

\subsection{Work satisfaction}

The concept of job satisfaction represents an emotional response of the employee to various aspects and work conditions and is also the result of his subjective perception of the degree to which work gives him the elements he considers important. Job satisfaction is an emotional state that cannot be measured but only deduced from the employee's work behaviors and performance. According to Vercellino (2008) job satisfaction refers to the degree to which a person is satisfied with different aspects of his own service, implying that a reason is achieved, a need fulfilled and a goal achieved. In order to develop the job satisfaction, it is 
essential for the employees to find the meaning in their work so that they can always perform their work tasks with enthusiasm and interest wholeheartedly, regardless of whether they are employed in part-time or full time jobs. There are areas that, under certain circumstances, cause dissatisfaction at work, but people are forced to develop positive feelings and bring effective solutions to all kinds of issues and difficulties. Job satisfaction involves a multifunctional number of variables, circumstances, situations, views, and behavioral tendencies [5].

\section{Previous research that has addressed job satisfaction depending on the communication style and behavior in conflict situations}

Downs and Hazen (1977) used eight communication factors in order to test the effects on job satisfaction. Their study found that personal feedback, supervisory communication and communication climate were the three factors that correlated mostly with job satisfaction [6].

Pinchus (1986a, 1986b) presented a research model that proved that relational dimensions of communication (such as communication between subordinates and supervisor) would be more strongly related to job satisfaction than informational dimensions (e.g., media quality, organizational integration). ). By using a sample of nurses, Pinchus (1986a, 1986b) found some support for the differential sensitivity of job satisfaction to the relational and informational dimensions of communication, although both were significantly related to job satisfaction [7].

In another study, Clampitt and Downs (1993) found that supervisory communication and subordinate communication were the two factors that interacted the most with job satisfaction, while personal feedback provided the lowest correlation with job satisfaction [8].

Akkirman and Harris (2005) measured the following six factors: the employee's relationship with supervisor, communication climate, overall communication satisfaction, horizontal communication, organizational integration, and personal feedback. They found that teleworkers have higher levels of communication satisfaction across all factors compared to traditional office workers [9].

Wright and Brajtman (2011) examined the role of communication skills in predicting conflict style, job satisfaction, work stress, and job loss among health care workers. The results indicated that scores on higher communication skills were predictive for compromise and adjustment as conflict styles among health care workers, although scores on lower communication skills were predictive for facing and avoidance of conflict styles. In addition, a compromised conflict style was predictive for mitigating stress and increasing job satisfaction, while facing and avoiding conflict styles was predictable by an increase in the workforce among participants [10].

Research conducted by Marino and Faktol (apud Farahbod, 2013) has shown that there is a positive relationship between time spent in communication and important activities, such as actions that lead to job satisfaction. According to the research, the employee's behavior is influenced by their own attitudes, therefore, their awareness is essential for managers [11]. Awan \& Saeed, (2015) suggested that open communication can be assessed as a conflict settlement technique. Spaho (2013) conducted a study on organizational communication and conflict management. The researcher showed that it is not possible to imagine organizational communication without conflict. All levels of management have the responsibility to manage the conflict. The researcher also pointed out that possible conflict management techniques should be used in appropriate situations [12]. 
Kassim \& Ibrahim (2014) studied in Malaysia in order to reveal the technique of conflict settlement and showed that employees are more dedicated to the organization by using the style of integration in conflict settlement. On the other hand, employees considered that dominant and avoidant styles significantly decrease the organizational commitment [13].

Hossain (2015) showed the causes, effects and strategies of conflict in the private sector and found that top-down communication, gender discrimination, job dissatisfaction, poor time management, nepotism are the main cause of conflict [14].

\section{Research}

\subsection{Purpose}

This study was designed in order to test the relationship between job satisfaction, communication style and conflict behavior of employees in the public system, respectively within the territorial labor inspectorates.

\subsection{Research methodology}

\subsubsection{Three working tools were used in order to test the research assumptions:}

I. The Communication Styles questionnaire, drafted by the Romanian psychologist S. Marcus, used to measure the communication style. The test is relevant for the 4 fundamental styles of communication: assertive, non-assertive, manipulative and aggressive.

II. Thomas Kilmann's conflict settlement test, used to measure the behavior in conflict situations, which assesses the ability to settle conflicts, used by the individual in different situations, through which can be identified: competitive style, adaptive style, collaborative style, compromise style, avoidance style.

III. The SP job satisfaction questionnaire (Constantin T., 2004), for measuring job satisfaction, a tool that covers 4 factors: remuneration and promotion, leadership and interpersonal relationships, organization and communication and general satisfaction.

\subsubsection{Target group:}

The target group of the study, from which a number of 75 subjects were sampled, consisted of employees from labor inspectorates, using small and independent samples of subjects.

\subsubsection{Method:}

The research was carried out in 2020 in 7 labor inspectorates, therefore the activity is standardized in terms of the same operational and system procedures. The application of the 3 questionnaires was made with observing the standards regarding the information and training of the respondents. Finally, the questionnaires were collected, creating a database that was later used to process the results, respectively for the statistical interpretation of data by using the SPSS software.

\subsection{Research assumptions}

\subsubsection{Main assumption no.1:}


There are significant correlations, positive and negative, between job satisfaction, communication style (assertive / non-assertive / manipulative / aggressive) and behavior in conflict situations (adaptation / avoidance / compromise / collaboration / facing) of employees - public officials. Secondly there is a significant positive correlation between job satisfaction and assertive communication style, collaborative conflict behavior, conflict adaptation behavior and there is a significant negative correlation between job satisfaction and non-assertive communication style, manipulative communication, aggressive communication style, compromised behavior in conflicts, confrontational behavior in conflicts.

\subsubsection{Main assumption no. 2:}

Assertive and non-assertive communication style and behavior in situations of conflict type adaptation and compromise are significant predictors for job satisfaction.

\subsection{Variables}

\subsubsection{Dependent variable:}

VD1 - job satisfaction: remuneration and promotion / leadership and interpersonal relationships / organization and communication;

\subsubsection{Independent variables:}

VI1 - communication style: assertive / non-assertive / manipulative / aggressive; VI2 behavior style in conflict situations: adaptation / avoidance / compromise / collaboration / confrontation.

\section{Research results and interpretations}

The analysis and interpretation of the results was performed by using the specialized program of psychological statistics SPSS 20. The following statistical analysis were performed: Pearson correlations; Multiple linear regression; Significance test of the difference between t-student environments for independent samples; ANOVA one-way for comparing environments.

\subsection{Results interpretation for the main assumption no. 1}

The first secondary hypothesis, respectively the results obtained by calculating the Pearson correlation coefficient partially confirm the research assumptions (assertive - job satisfaction $r=0.268, p=0.020<0.05$; collaboration - job satisfaction $r=-0.061, p=0.600>$ 0.05 , adaptation - job satisfaction $r=0.274, p=0.017<0.05$ ), in the meaning that there is a statistically significant correlation between assertive communication style and job satisfaction and the positive relationship valid for $7.2 \%$ of the subjects $(\mathrm{r} 2=0.072$ ) respectively a statistically significant correlation between adaptation type in conflicts and job satisfaction and the positive relationship valid for $7.5 \%$ of the subjects $(\mathrm{r} 2=0.075)$. For the second secondary hypothesis, the results achieved by calculating the Pearson correlation coefficient partially confirm the research assumptions (non-assertive - job satisfaction $r=$ $0.275, \mathrm{p}=0.017<0.05$; manipulative - job satisfaction $\mathrm{r}=-0.181, \mathrm{p}=0.120>0.05$, aggressive 
- job satisfaction $\mathrm{r}=-0.041, \mathrm{p}=0.726>0.05$, compromise - job satisfaction $\mathrm{r}=-0.301, \mathrm{p}=$ $0.009<0.05$, confrontation - job satisfaction $\mathrm{n}$ work $\mathrm{r}=-0.196, \mathrm{p}=0.093>0.05)$, in the meaning that there is a statistically significant correlation between non-assertive communication style and job satisfaction and the negative relationship valid for $7.6 \%$ of subjects $(\mathrm{r} 2=0.076)$ respectively a statistically significant correlation between compromised behavior in conflicts and job satisfaction and the negative relationship valid for $9 \%$ of subjects $(\mathrm{r} 2=0.090)$. Thus, we can mention the fact that as the scores on the non-assertive communication style and those on compromised behavior in conflicts will increase, the ones from job satisfaction, respectively the inverse relationship, will decrease. Regarding the manipulative communication style, aggressive communication style, confrontational behavior in conflicts and job satisfaction, there is no statistically significant correlation.

Table 1. Results obtained when calculating Pearson Correlations for research hypothesis no.1.

\begin{tabular}{|c|c|c|}
\hline \multicolumn{2}{|c|}{ Correlations } & work satisfaction \\
\hline & $\mathrm{N}$ & 75 \\
\hline \multirow{3}{*}{ adaptation } & Pearson Correlation & $.274^{*}$ \\
\hline & Sig. (2-tailed) & .017 \\
\hline & $\mathrm{N}$ & 75 \\
\hline \multirow{3}{*}{ avoidance } & Pearson Correlation & .176 \\
\hline & Sig. (2-tailed) & .131 \\
\hline & $\mathrm{N}$ & 75 \\
\hline \multirow{3}{*}{ compromise } & Pearson Correlation & $-.301^{* *}$ \\
\hline & Sig. (2-tailed) & .009 \\
\hline & $\mathrm{N}$ & 75 \\
\hline \multirow{3}{*}{ collaboration } & Pearson Correlation & -.061 \\
\hline & Sig. (2-tailed) & .600 \\
\hline & $\mathrm{N}$ & 75 \\
\hline \multirow{3}{*}{ confrontation } & Pearson Correlation & -.196 \\
\hline & Sig. (2-tailed) & .093 \\
\hline & $\mathrm{N}$ & 75 \\
\hline \multirow{3}{*}{ assertive } & Pearson Correlation & $.268^{*}$ \\
\hline & Sig. (2-tailed) & .020 \\
\hline & $\mathrm{N}$ & 75 \\
\hline \multirow{3}{*}{ non-assertive } & Pearson Correlation & $-.275^{*}$ \\
\hline & Sig. (2-tailed) & .017 \\
\hline & $\mathrm{N}$ & 75 \\
\hline \multirow{3}{*}{ manipulative } & Pearson Correlation & -.181 \\
\hline & Sig. (2-tailed) & .120 \\
\hline & $\mathrm{N}$ & 75 \\
\hline \multirow{3}{*}{ aggressive } & Pearson Correlation & -.041 \\
\hline & Sig. (2-tailed) & .726 \\
\hline & $\mathrm{N}$ & 75 \\
\hline
\end{tabular}


From the point of view of psychological interpretation, considering these assumptions we find that for the target group is confirmed the significant positive correlation of job satisfaction with the assertive communication style that is supported by the literature, namely that people with assertive communication style can express themselves with avoiding aggression, in different situations, enjoying emotional well-being. Thus, assertiveness as a tool can help in initiating and maintaining qualitative social relationships and will therefore contribute to high job satisfaction. The confirmation of the assumptions according to which there is a significant positive correlation between adaptation behavior in conflicts with job satisfaction, is supported by the fact that those who fall into this category act to meet the needs of others and this creates a satisfactory work environment for them. Such a strategy is a preferred way of approaching the conflict when the aggressiveness of the other party would involve an unacceptable behavior, involving the maintenance of interpersonal relationships for any purpose and therefore provides a work environment that satisfies him professionally. Regarding the significant negative correlation of job satisfaction with the non-assertive communication style, respectively of the compromised behavior in conflicts, it is highlighted by the fact that those who fall into this category of sacrifice of personal interests and avoidance of situations that involve taking the initiative or important decisions, leads to the development of negative feelings, frustration, anger, sadness, and maladaptive behaviors, moments of outburst, maintaining costly social relationships for the individual, aspects that spread fully towards job satisfaction that will be low.

\subsection{Results interpretation for the main assumption no. 2}

By applying multiple stepwise regression, it was verified whether the four variables correlating with job satisfaction can be used as significant predictors in order to predict the scores of the dependent variable. According to the regression analysis we find the following statistical situation:

Table 2. Excluded Variables.

\begin{tabular}{|c|c|c|c|c|c|c|c|c|}
\hline \multirow{2}{*}{\multicolumn{2}{|c|}{ Model }} & \multirow[b]{2}{*}{ Beta In } & \multirow[b]{2}{*}{$t$} & \multirow[b]{2}{*}{ Sig. } & \multirow[b]{2}{*}{$\begin{array}{c}\text { Partial } \\
\text { Correlation }\end{array}$} & \multicolumn{3}{|c|}{ Collinearity Statistics } \\
\hline & & & & & & Tolerance & $V I F$ & $\begin{array}{l}\text { Minimum } \\
\text { Tolerance }\end{array}$ \\
\hline \multirow{3}{*}{1} & assertive & $.204^{b}$ & 1.792 & .077 & .207 & 932 & 1.072 & .932 \\
\hline & Non-assertive & $-.245^{b}$ & -2.238 & .028 & -.255 & .988 & 1.013 & .988 \\
\hline & adaptation & $.211^{b}$ & 1.856 & .068 & .214 & 933 & 1.071 & .933 \\
\hline \multirow{2}{*}{2} & assertive & $.122^{c}$ & .987 & .327 & .116 & 778 & 1.285 & .778 \\
\hline & adaptation & $.191^{c}$ & 1.719 & .090 & .200 & 927 & 1.079 & .926 \\
\hline
\end{tabular}

- assertive communication style, $\mathrm{B}=0.122, \mathrm{t}=0.987, \mathrm{p}=0.327>0.05$, these values indicate that this variable is an insignificant predictor of the criterion;

- behavior in adaptation conflict situations, $\mathrm{B}=0.191, \mathrm{t}=1.719, \mathrm{p}=0.090>0.05$ these values indicate that this variable is an insignificant predictor of the criterion;

Authors should use the forms shown in Table 3 in the final reference list.

Table 3. ANOVA.

\begin{tabular}{|c|l|l|l|l|c|c|}
\hline \multicolumn{2}{|c|}{ Model } & Sum of Squares & df & Mean Square & F & Sig. \\
\hline \multirow{3}{*}{1} & Regression & 4.120 & 1 & 4.120 & 7.260 & $.009^{\mathrm{b}}$ \\
\cline { 2 - 7 } & Residual & 41.427 & 73 & .567 & & \\
\cline { 2 - 7 } & Total & 45.547 & 74 & & & \\
\hline \multirow{2}{*}{}
\end{tabular}




\begin{tabular}{l}
\begin{tabular}{|l|l|l|l|l|l|l|}
\hline & Regression & 6.816 & 2 & 3.408 & 6.335 & $.003^{\mathrm{c}}$ \\
\cline { 2 - 7 } & Residual & 38.731 & 72 & .538 & & \\
\cline { 2 - 5 } & Total & 45.547 & 74 & & & \\
\hline
\end{tabular} \\
$\begin{array}{l}\text { a. Dependent Variable: work satisfaction } \\
\text { b. Predictors: (Constant), compromise } \\
\text { c. Predictors: (Constant), compromise, non-assertive }\end{array}$ \\
\hline
\end{tabular}

- behavior in compromised conflict situations, $\mathrm{B}=-0.104, \beta=-0.273, \mathrm{t}=-2,500, \mathrm{p}=$ $0.015<0.05$, the variance of the criterion job satisfaction is explained by this predictor in proportion of $9 \%$ and $\mathrm{F}(1.73)=7.260, \mathrm{p}=0.009<0.05$.

- non-assertive communication style, $\mathrm{B}=-0.067, \beta=-0.245, \mathrm{t}=-2.238, \mathrm{p}=0.028<0.05$ the variance of the job satisfaction criterion is explained by this predictor in proportion of $6 \%$ and $\mathrm{F}(1,73)=6,335, \mathrm{p}=0.003<0.05$.

Table 4. Values of beta regression coefficients.

\begin{tabular}{|c|c|c|c|c|c|c|c|c|c|c|c|}
\hline \multicolumn{12}{|c|}{ Coefficients $^{\mathrm{a}}$} \\
\hline \multirow{2}{*}{\multicolumn{2}{|c|}{ Model }} & \multicolumn{2}{|c|}{$\begin{array}{c}\text { Unstandardized } \\
\text { Coefficients }\end{array}$} & \multirow{2}{*}{$\begin{array}{c}\begin{array}{c}\text { Standardized } \\
\text { Coefficients }\end{array} \\
\text { Beta }\end{array}$} & \multirow{2}{*}{$\mathrm{t}$} & \multirow{2}{*}{ Sig. } & \multicolumn{3}{|c|}{ Correlations } & \multicolumn{2}{|c|}{$\begin{array}{c}\text { Collinearity } \\
\text { Statistics }\end{array}$} \\
\hline & & B & $\begin{array}{l}\text { Std. } \\
\text { Error }\end{array}$ & & & & $\begin{array}{l}\text { Zero- } \\
\text { order }\end{array}$ & Partially & Part & Tolerance & VIF \\
\hline & (Constant) & 5.201 & .319 & & $\begin{array}{l}16 . \\
287\end{array}$ & $\begin{array}{l}.00 \\
0 \\
\end{array}$ & & & & & \\
\hline 1 & compromise & -.114 & .042 & -.301 & $\begin{array}{l}- \\
2.6 \\
94\end{array}$ & $\begin{array}{l}.00 \\
9\end{array}$ & - & -.301 & \begin{tabular}{|l|} 
\\
.30 \\
1 \\
\end{tabular} & 1.000 & $\begin{array}{l}1.00 \\
0\end{array}$ \\
\hline & (Constant) & 5.506 & .340 & & $\begin{array}{l}16 . \\
219\end{array}$ & $\begin{array}{l}.00 \\
0\end{array}$ & & & & & \\
\hline 2 & compromise & -.104 & .042 & -.273 & $\begin{array}{l}- \\
2.5 \\
00\end{array}$ & $\begin{array}{l}.01 \\
5\end{array}$ & $-\overline{.301}$ & -.283 & $\begin{array}{l}- \\
.27 \\
2\end{array}$ & .988 & $\begin{array}{l}1.01 \\
3\end{array}$ \\
\hline & $\begin{array}{l}\text { Non- } \\
\text { assertive }\end{array}$ & -.067 & .030 & -.245 & $\begin{array}{l}- \\
2.2 \\
38\end{array}$ & $\begin{array}{l}.02 \\
8\end{array}$ & $\begin{array}{l}- \\
.275\end{array}$ & -.255 & \begin{tabular}{|l}
- \\
.24 \\
3 \\
\end{tabular} & .988 & $\begin{array}{l}1.01 \\
3\end{array}$ \\
\hline
\end{tabular}

Thus, there are two independent variables that explain about $15 \%$ of the criterion variance. The partial correlation for the variable behavior in conflict situations of compromised type and non-assertive communication style is -0.272 , respectively -0.243 , values which, in the square, justify in proportion of $7 \%$, respectively $6 \%$ the variance to job satisfaction, when their common variance is not taken into account.

Since the total percentage of variance that the two variables y is $15 \%$, it means that the percentage of variance they share is about $2 \%(15 \%-13 \%)$. Both values of beta regression coefficients are negative (compromised behavior, non-assertive communication style), thus there is a negative relationship between each predictor and the dependent variable (job satisfaction). T values plus Sig values. indicates that the two independent variables contribute significantly to the improvement of the prediction, thus confirming the initial assumption in part. 


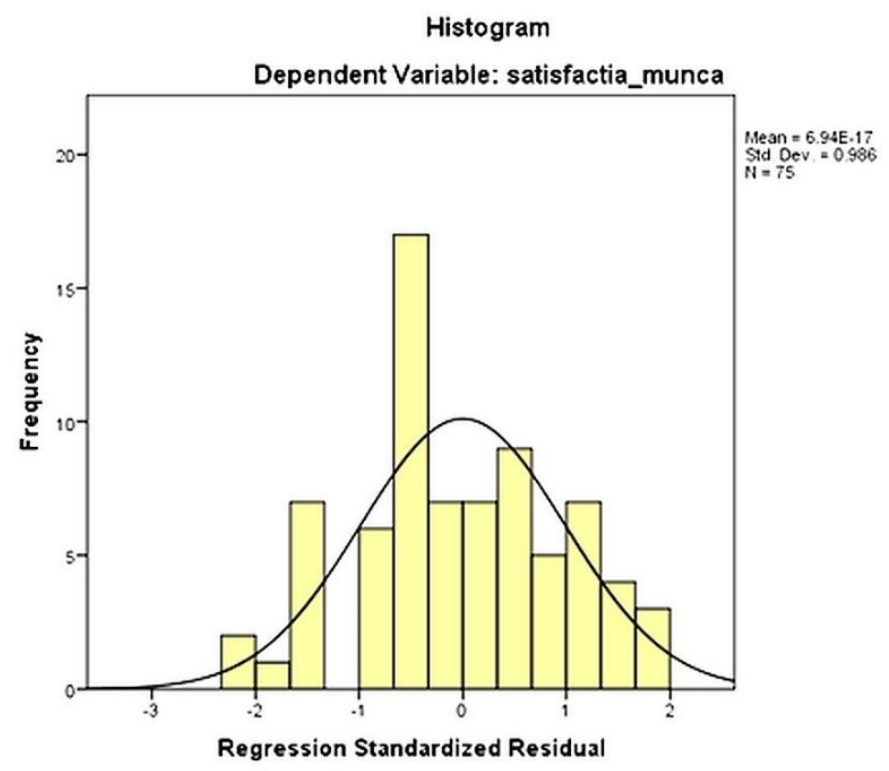

Fig. 1. Histogram of the dependent variable: work satisfaction.

From the point of view of psychological interpretation, the result is in agreement with the previous assumption regarding the negative correlations between job satisfaction and nonassertive communication style, respectively the behavior in compromised conflict situations. It is observed from this analysis that the best predictive model is the one provided by both variables, but the variance explained by this model remains low. As mentioned before, as the scores for non-assertive communication style and those for compromised behavior in conflicts will decrease, those for job satisfaction will increase. Therefore, if the people who fit into these two situations of relationship management first of all become aware of their own model of response to communicative and relational level in conflict situations and later take measures of tempering and efficiency, they will end up experiencing increased work satisfaction.

\section{Conclusions - limitations and proposals}

The results obtained in this research, which target group were civil servants from the labor inspectorates, show that job satisfaction is directly and indirectly proportional to the variables of communication style and type of conflicting behavior, even in a significant measure. Summarizing the present results, we can highlight the following contributions to the field of research:

a. there is a statistically significant correlation between assertive communication style and job satisfaction, the positive relationship being valid for $7.2 \%$ of subjects, respectively a statistically significant correlation between conflict adaptation behavior and job satisfaction, the positive relationship being valid for $7.5 \%$ of the subjects, therefore as the scores on the assertive communication style and those on the adaptive behavior in conflicts will increase, the ones on job satisfaction will also increase.

b. there is a statistically significant correlation between non-assertive communication style and job satisfaction, the negative relationship being valid for $7.6 \%$ of subjects, respectively a statistically significant correlation between compromised behavior in conflicts 
and job satisfaction, negative relationship being valid for $9 \%$ of the subjects, therefore as the scores for the non-assertive communication style and those for the compromised behavior in conflicts will increase, the ones from work satisfaction, respectively the inverse relationship, will decrease;

c. there are two independent variables, the behavior in compromised conflict situations and the non-assertive communication style that significantly contributes to the improvement in the prediction, explaining in $15 \%$ the variance of the criterion, job satisfaction, through a negative relationship.

Given the results presented, we can say that the research plan has achieved its goal of testing the relationship between job satisfaction, communication style and conflict behavior of employees of labor inspectorates and the assessment goals with methods standardized and scientific assumptions which value and usefulness can be tested at a practical, personal and collective professional level. The research responds to some practical needs highlighted by the organizational psychology, but which were not customized for civil servants, to identify the prevailing sources and those dimensions that make the individual's perception of the organization lead to increased job satisfaction. However, the paper is not without methodological limits, undertaken from the beginning of the research, represented by the use of self-reporting assessment questionnaires that could involve poor identification and reporting, through the tendency that occurs when the subject is not honest in filling in the questionnaire, when he gives answers that do not reflect his true feelings, principles and values, when he tends to avoid answers appropriate to their condition, just to make a good impression, to determine a positive judgment, to place themselves in -a situation of appreciation, either out of the desire to help the researcher in confirming the study assumption, that he thinks it would imply.

However, the paper provides additional information for the scientific community, and can also be a starting point for other research by methodological improvement and by bringing to the fore certain variables that can make a significant contribution to the work satisfaction for civil servants, since the topic is of maximum interest given the current context when it is desired a qualitative increase in services for employees and employers.

\section{References}

1. H. Steingrimsdottir, The relationship between internal communication \& job satisfaction: A case study, (Copenhagen Business School: Marketing Communication Management, 2011)

2. S.K. Gupta, R. Joshi, Organizational Behavior, (Kalyani Publishers, NewDelhi, 2008)

3. M. Zlate, Treatise on organizational-managerial psychology, (Ed Polirom, Iasi, 2008)

4. K. A. Slaikeu, R. H. Hasson, Controlling the Cost of Conflict: How to Design a System for Your Organization, (CA, Jossey-Bass, San Francisco, 1998)

5. I. Verboncu, M. Zalman, Management şi performanţe, (Editura Universitară, Bucureşti, 2005).

6. C. Downs, M. Hazen, Journal of Business Communication 14, 63-73 (1977)

7. J. D. Pinchus, Human Communication Research 12, 395-419 (1986a)

8. P.G. Clampitt, C.W. Downs, Journal of Business Communication 30 (1), 5-28 (1993)

9. A. D. Akkirman, D. L. Harris, Journal of Management Development 24 (5), 397-409 (2005)

10. D. Wright, S. Brajtman, Nursing Ethics 18 (1), 20-30 (2011)

11. F. Farahbod, S. B. Salimi, K. R. Dorostkar, Journal of Contemporary Research In Business 5, 4 (2013)

12. A. G. Awan, S. Saeed, Research Journal of Finance and Accounting 6, 11 (2015)

13. M. A. M. Kassim, H. I. Ibrahim, International Journal of Business, Economics and Law 4, 1 (2014)

14. M. M. Rahman, T. Hossain, Conflict in Bangladeshi Organization: Causes, Effects and Strategies, Banglavision Research Journal 15, 1 (2015) [Online]. Available: http://bv-f.org/VOL15/02.\%20BV\%20Final.pdf [Accessed 20 July 2021] 